\section{Detonation of Liquid Explosives by Impact}

Auтнолgн a considerable amount of experimental work has been done on the impact sensitivity of liquid explosives, the mechanism of initiation by mechanical shock is not fully understood. Furthermore, the values for sensitivity obtained by different workers showed marked variations. With nitroglycerine, for example, the figures quoted range from $14,000 \mathrm{gm}$. cm. ${ }^{1,2,3}$ down to $500 \mathrm{gm}$. cm. (sensitivity given as the product of mass of striker in gm. multiplied by height of fall in $\mathrm{cm}$.). An attempt has been made to investigate in more detail the physical processes which occur during impact, and to study the mechanism of the initiation and growth of $\theta \mathrm{x}$ plosion 4,5 .

One observation which is of general interest is the profound effect which minute bubbles of included gas have on the impact sensitivity of the explosivese. It is found that, under many conditions of impact, minute bubbles are present or are entrapped in the explosive. If one of the surfaces contains a small pinhole or cavity, inclusion of air almost invariably occurs during impact, and even if smooth flat surfaces are used, air is entrapped if the distribution of the explosive is not uniform. If a small amount of gas is present, the explosive may be detonated by the gentlest of blows. With nitroglycerine, for example, when a bubble as small as $5 \times 10^{-3} \mathrm{~cm}$. in radius is present, an explosion may occur with the impact of $40 \mathrm{gm}$. falling $0.5 \mathrm{~cm}$. (impact energy $20 \mathrm{gm}$. cm., rate of approach of surfaces $30 \mathrm{~cm}$./sec.). In the absence of gas bubbles, impact energies of the order of $10^{5}-1 C^{6} \mathrm{gm}$. $\mathrm{cm}$. and high rates of approach are necessary. The initiation is due to the adiabatic compression and heating of the entrapped bubble. Although the limiting sensitivity varies with different explosives, the effect is quite general and applies to all the liquid, gelatinous and plastic explosives which have so far been studied. It also applies to solid explosives if they are melted or are dissolved in various organic solvents such as benzene and dioxan.

There is some evidence that explosion can take place when the pressure ratio is about $20: 1$, and approximate calculations suggest that the temperature rise in the gas bubble must be $c .400^{\circ} \mathrm{C}$. for initiation to occur, but it is usually considerably greater. If a gas of low $\gamma$, such as ether $(\gamma=1.08)$ or carbon tetrachloride $(\gamma=1 \cdot 13)$ is used instead of air $(\gamma=1 \cdot 4)$, the sensitivity is correspondingly decreased.

It is probable that initiation occurs in the vapour phase inside the bubble. The explosion spreads outwards from this tiny hot bubble and is propagated through the surrounding explosive. Photographic and electric measurements show that initiation occurs at, or a few microseconds after, the first moment of impact, and the explosion, which begins at the bubble as a comparatively gentle burning, is rapidly transformed into a more violent explosion with a velocity exceeding 1,000 metres a second. Experiments at low pressure show that the amount of included gas necessary to render the explosive sensitive to these small impacts is minute. The mass of entrapped gas can be as small as $3 \times 10^{-11} \mathrm{gm}$., and the quantity of heat developed within the bubble during its compression only c. 10-7 calories. Bubbles of this size may easily be entrapped under many conditions of laboratory and practical operation. Since they are difficult to see even with a microscope, they readily escape detection and, under appropriate conditions, they may constitute a serious hazard.

\section{F. P. BOWDEN. \\ M. F. R. MUloahy. \\ R. G. VINES. \\ A. YoFrF.}

Lubricants and Bearings Section,

Council for Scientific and Industrial Research, University of Melbourne.

1 Berthmann, A., Chem. Abst., 35, 625 (1941).

${ }^{2}$ Will, Z. ges. Schiess u. Sprenstoffwesen., 209 (1906).

3 Naoum, P., "Nitroglycerine and Nitroglycerine Explosives" (Balti more, 1928).

- Bowden, F. P., Eirich, F., Ferguson, A. E., and Yoffe, A., Coun. Sci. Indust. Res. (Aust.) Bull., 167 (1943).

5 Bowden, F. P., Eirich, F., Mulcahy, M. F. R., Vines, R. G., and Yoffe, A., Coun. Sci. Indust. Res. (Aust.) Bull., 173 (1943).

'Bowden, F. P., Mulcahy, M. F. R., Vines, R. G., and Yoffe, A., Coun. Sci. Indust. Res. (Aust.) Lubricants and Bearings Report A. 113 , No. 7 (December 1944)

\section{Carriage of Plague by the Common Brown Rat (Rattus norvegicus)}

IN Nature of December 8 it is asserted, without comment, that the common rat of Britain (Rattus norvegicus) does not carry plague ${ }^{1}$.

This belief often arises because plague in the Middle Ages was, at least in Western Europe, carried by the 'black' rat, $R$. rattus; at that time $R$. norvegicus had not spread so far ${ }^{2}$. The spread of $R$. norvegicus, and the decline of $R$. rattus since the beginning of the eighteenth century, have taken place in a period during which there has been relatively little plague in Europe.

The absence of plague is, however, not attributable simply to the absence of $R$. rattus. $R$. norvegicus is well known to be a vector of plague ${ }^{3}$. A clear instance of the relationship between infection of this species and human infection is provided by the recent outbreak in Malta.

The outbreak began in June 1945. The dominant rat in Malta is $R$. norvegicus, which is of general occurrence both in towns and countryside, and even in the port and dockyard areas. During the period October 1944 to September 1945, of the rats examined in the Government laboratories, 36,376 were $R$. norvegicus and 2,903 were $R$. rattus. Up to December $1,1945,17$ rats had been shown to be infected with plague. Of these, 12 were $R$. norvegicus. One of the foci of infection was the small inland village of Zurrieq, where there were 14 human cases during the period June 23-August 7, 1945. Here $R$. norvegicus was clearly implicated: the first four infected rats were caught in this area, and were all of this species. Three of them were taken from a refuse heap, and Dr. J. Morana, the medical officer of health, clearly established the relationship between this refuse collection and infection of human beings.

The figures of rats examined, and of rats shown to be infected with plague, have been kindly supplied by Prof. V. J. Mifsud, analyst and bacteriologist to the Government of Malta.

Ministry of Food Infestation Control

\section{S. A. Barnett.} Gower Street, London, W.C.1.

${ }^{1}$ Russell, E. J., Nature, 156, 675 (1945).

Barrett-Hamilton, G. E. H., and Hinton, M. A. C., "History of British Mammals" (1910-21).

"See Wu Lien-Teh, et al., "Plague"' (Shanghai, 1936), Strong, R. P., "Stitt's Tropical Diseases" (London, 1942). 